The authors reported no conflicts of interest.

The Journal policy requires editors and reviewers to disclose conflicts of interest and to decline handling or reviewing manuscripts for which they may have a conflict of interest. The editors and reviewers of this article have no conflicts of interest.

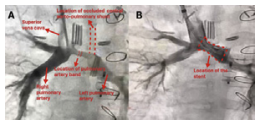

\section{MANAGEMENT FOR \\ BIDIRECTIONAL \\ CAVOPULMONARY \\ SHUNT FAILURE: \\ ADDING \\ AORTOPULMONARY \\ SHUNT WITHOUT}

\section{TAKEDOWN}

\section{To the Editor:}

We read with great interest the article entitled "Low Preoperative Superior Vena Cava Blood Flow Predicts Bidirectional Cavopulmonary Shunt Failure" by Luo and colleagues. ${ }^{1}$ The authors appreciably demonstrated that low preoperative superior vena cava blood flow was associ-

\footnotetext{
The Editor welcomes submissions for possible publication in the Letters to the Editor section that consist of commentary on an article published in the Journal or other relevant issues. Authors should: • Include no more than 500 words of text, three authors, and five references. • Type with double-spacing. • See http://jtcs.ctsnetjournals.org/ misc/ifora.shtml for detailed submission instructions. - Submit the letter electronically via jtcvs.editorialmanager.com. Letters commenting on an article published in the JTCVS will be considered if they are received within 6 weeks of the time the article was published. Authors of the article being commented on will be given an opportunity of offer a timely response ( 2 weeks) to the letter. Authors of letters will be notified that the letter has been received. Unpublished letters cannot be returned.
}

ated with low arterial saturation and poor clinical outcome following bidirectional cavopulmonary shunt (BCPS). We congratulate the authors for this inspiring study; however, we would like to add some comments on one aspect. In this study, the authors performed BCPS takedown on the patients who had BCPS failure. Many studies have shown that this approach has a high mortality rate. ${ }^{1-3}$ We would like to mention an alternative treatment for BCPS failure without BCPS takedown.

Over the past 3 years, we encountered BCPS failure in 2 patients. In the first patient with unbalanced atrioventricular septal defect, we performed extensive pulmonary arterioplasty and atrioventricular valve repair during BCPS procedure. Similarly, hilum-to-hilum arterioplasty and ductal stent removal were performed in the second case. In both cases, systemic oxygen saturation after weaning from CPB varied between $50 \%$ and $60 \%$ and the central venous pressure (CVP) was 16 to $18 \mathrm{~mm} \mathrm{Hg}$. Due to persistent low saturation, we decided to add an aortopulmonary shunt to the left of the BCPS anastomosis with a 4-mm polytetrafluoroethylene graft. Also, tight pulmonary banding was performed using a thin piece of 4-mm polytetrafluoroethylene graft ( $2 \mathrm{~mm}$ in width) that was placed between the anastomosis of BCPS and the aortopulmonary shunt. Systemic oxygen saturation increased to $70 \%$ to $75 \%$ in both cases and CVP increased to 19 to $20 \mathrm{~mm} \mathrm{Hg}$. About 1.5 to 2 hours after the shunt and banding, CVP decreased below $18 \mathrm{~mm} \mathrm{Hg}$.

In the first case, the aortopulmonary shunt thrombosis was detected approximately 1 month later. Therefore, the patient underwent transcatheter intervention. Balloon dilation and stenting of the banded segment of pulmonary artery was performed, and a balanced blood flow was achieved to both pulmonary arteries from BCPS (Figure 1, $A$ and $B$ ).

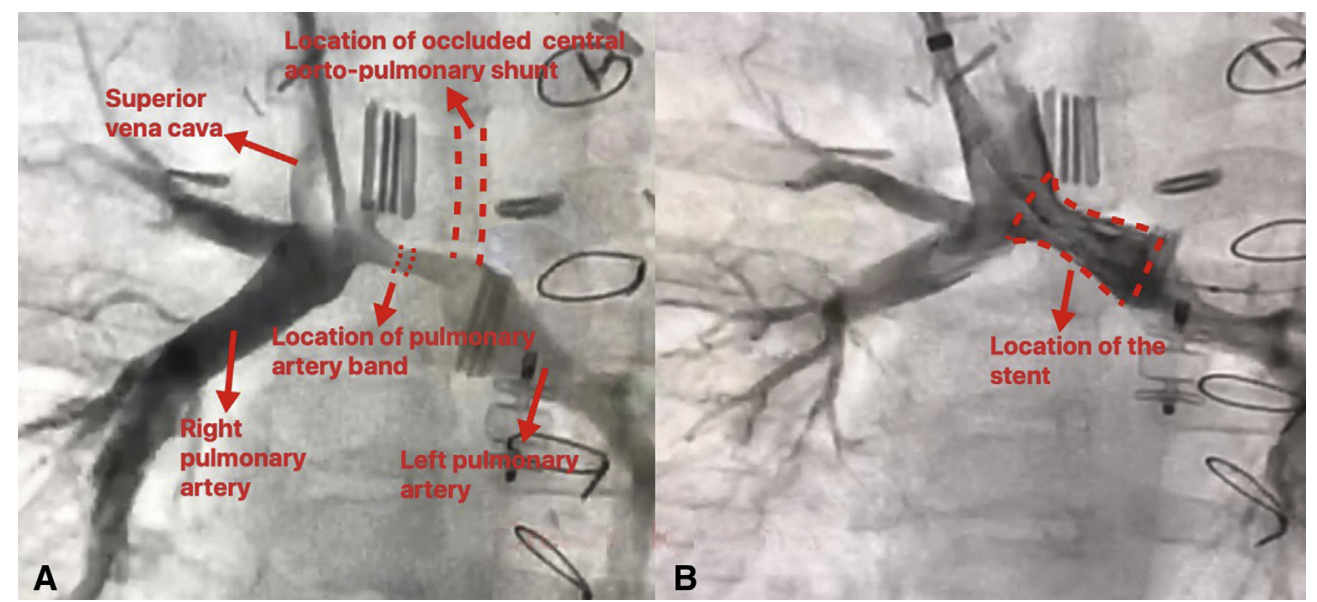

FIGURE 1. Cineangiography of pre-dilatation (A) and post-dilatation (B) with stent placement of the banded segment of the pulmonary artery from left side of the BCPS anastomosis toward left pulmonary artery. 
The second case remained stable with patent aortopulmonary shunt and BCPS. Both patients still remain stable with a systemic saturation of $75 \%$ to $87 \%$.

By adding an aortopulmonary shunt to the left of the BCPS without takedown and placing a tight band between the aortopulmonary shunt and the BCPS, systemic oxygen saturation raised over $75 \%$ while only a +1 - to $2-\mathrm{mm} \mathrm{Hg}$ increase in the Glenn pressure was seen in our cases. For attaching each tip of band, we used 6-0 polypropylene suture, which is thin enough to allow and facilitate transcatheter dilation of banding segment. Thus, it enabled transcatheter debanding during follow-up (Figure 1, $B$ ).

This approach has been used for unilateral pulmonary arterial obstruction/hypoplasia to increase the pulmonary blood flow. Casella and colleagues ${ }^{4}$ referred this approach as the "Super Glenn" approach. In conclusion, this technique can be a life-saving strategy in early deep hypoxemia and BCPS failure without BCPS takedown.

Rıza Türköz, $M D$

Abdullah Doğan, $M D$

Department of Cardiovascular Surgery Acibadem Bakirkoy Hospital

Istanbul, Turkey

\section{References}

1. Luo S, Haranal M, Deng MX, Varenbut J, Runeckles K, Steve Fan CP, et al. Low preoperative superior vena cava blood flow predicts bidirectional cavopulmonary shunt failure. J Thorac Cardiovasc Surg. May 4, 2020 [Epub ahead of print].

2. Cleveland JD, Tran S, Takao C, Wells WJ, Starnes VA, Kumar SR. Need for pulmonary arterioplasty during Glenn independently predicts inferior surgical outcome. Ann Thorac Surg. 2018;106:156-64.

3. Alejos JC, Williams RG, Jarmakani JM, Galindo AJ, Isabel-Jones JB, Drinkwater D, et al. Factors influencing survival in patients undergoing the bidirectional Glenn anastomosis. Am J Cardiol. 1995;75:1048-50.

4. Casella SL, Kaza A, Del Nido P, Lock JE, Marshall AC. Targeted increase in pulmonary blood flow in a bidirectional Glenn circulation. Semin Thorac Cardiovasc Surg. 2018;30:182-8.

https://doi.org/10.1016/j.jtcvs.2020.10.051

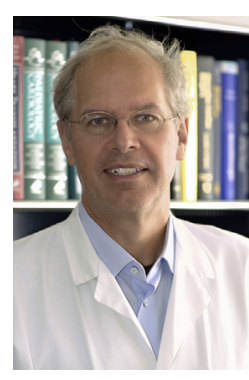

REPLY: ADDITIONAL "CUSTOMIZED" AORTOPULMONARY SHUNT MAY INCREASE "VIS A TERGO" TO RESCUE A FAILING BIDIRECTIONAL CAVOPULMONARY SHUNT

Reply to the Editor:

I discussed in my first Commentary that the necessity of an unrestricted passive systemic blood flow to the pulmonary artery is of paramount importance for the optimal function of a Fontan circulation. $^{1,2}$ As additional information, Türköz and
The authors reported no conflicts of interest.

The Journal policy requires editors and reviewers to disclose conflicts of interest and to decline handling or reviewing manuscripts for which they may have a conflict of interest. The editors and reviewers of this article have no conflicts of interest.

$\operatorname{Dogan}^{3}$ report on 2 cases in which an additional aorto-toleft pulmonary artery shunt with a banding performed between the Glenn anastomosis and the shunt to pulmonary artery anastomosis helped to manage a situation of a failing bidirectional cavopulmonary shunt. This shunt, with a minimal pulsatility, helped to increase the "vis a tergo" (a power from behind) that I had postulated as important feature for the success of a Glenn shunt. In fact, the solution proposed by the colleagues from Turkey was successful and contributed most probably to reduce the perioperative risks that may have been associated with a take-down. Both patients survived, had an improved oxygen saturation, and central venous pressure decreased slightly within hours.

I believe there are important aspects that may be discussed in relation to this additional report: the size of the shunt (3 instead of $4 \mathrm{~mm}$ ?) and the optimal technique to regulate the flow (and therefore the pressure gradient) across the shunt.

Another important point would be to discuss the optimal time point to disconnect the main pulmonary artery from the pulmonary bifurcation during the index procedure. One advantage of preserving the continuity would be that the shunt could be anastomosed to the main pulmonary trunk (perhaps easier in some instances because of the size) and the banding could be placed proximal to the bifurcation. This would eliminate the risk of additional intervention on the left pulmonary artery, even though this was successfully performed in the described case.

This may appear to be in contradiction to what I wrote in my first Commentary, eg, that one of the most important strategies to increase superior vena cava blood flow is probably the elimination of antegrade pulmonary blood flow that competes with superior vena cava flow. With the interposition of a tight banding, this contradiction may become relative only.

\section{Thierry Carrel, $M D$ \\ From the Department of Cardiovascular Surgery, University Hospital and University of Bern, Bern,}

Switzerland.

\section{References}

1. Luo S, Haranal M, Deng MX, Varenbut J, Runeckles K, Fan CPS, et al. Low preoperative superior vena cava blood flow predicts bidirectional cavopulmonary shunt failure. J Thorac Cardiovasc Surg. 2020;160:1529-40. 